Original Article

\title{
Effects of a resistance training program performed with an interocclusal splint for community-dwelling older adults: a randomized controlled trial
}

\author{
Tatsuya Hirase, PT, PhD ${ }^{1,2)}$, Shigeru Inokuchi, PT, PhD ${ }^{1 *}$, Nobuou Matsusaka, MD, PhD ${ }^{1)}$, \\ Kazumi Nakahara, PT, MS ${ }^{1}$, Minoru OKita, PT, PhD ${ }^{2)}$ \\ 1) Department of Health Sciences, Graduate School of Biomedical Sciences, Nagasaki University: 1-7-1 \\ Sakamoto, Nagasaki 852-8520, Japan \\ 2) Department of Locomotive Rehabilitation Science, Unit of Rehabilitation Sciences, Graduate School \\ of Biomedical Sciences, Nagasaki University, Japan
}

\begin{abstract}
Purpose] To examine whether resistance training for elderly community-dwellers performed with an interocclusal splint resulted in greater lower extremity muscle strength and better balance than resistance training performed without an interocclusal splint. [Subjects and Methods] Eighty-eight elderly persons using Japanese community day centers were randomly divided into two groups: an intervention group $(n=45)$, which performed resistance training with an interocclusal splint; and a control group $(\mathrm{n}=43)$, which performed resistance training without an interocclusal splint. The resistance training program comprised a 40-min session performed twice a week for 12 weeks. Outcome measures were the chair stand test (CST), timed up and go test (TUG), and one-leg standing test (OLST). Assessments were conducted before the intervention and every 2 weeks after the start of the intervention. [Results] There was a significant group $\times$ time interaction for the OLST, with the intervention group showing significant improvement from 8 to 12 weeks compared to the control group. For the CST and TUG, no significant differences were found between the two groups throughout the 12 weeks. [Conclusion] Resistance training with an interocclusal splint improved the balance ability of elderly community-dwellers more effectively than resistance training without an interocclusal splint. Key words: Resistance training, Interocclusal splint, Elderly
\end{abstract}

(This article was submitted Dec. 18, 2015, and was accepted Feb. 1, 2016)

\section{INTRODUCTION}

Physical functions such as lower extremity muscle strength, balance and walking ability deteriorate with age. Deterioration of physical function appears to be associated with disability in activities of daily living and an increased risk of falls among the community-dwelling elderly ${ }^{1,2}$. Various community exercise programs for improving physical function and activity levels are provided for the elderly who are at high risk of falls throughout Japan. Some systematic reviews have reported that resistance training programs effectively improve physical function parameters, such as lower extremity muscle strength and the gait speed of elderly persons ${ }^{3-5)}$. Moreover, a systematic review by Valenzuela ${ }^{5)}$ showed that resistance training programs are feasible and safe for elderly institutionalized subjects, because no study-related adverse events occurred and the attendance rate of the exercise group was high. Consequently, resistance training programs for improving the physical function of the elderly are both effective and feasible.

\footnotetext{
*Corresponding author. Shigeru Inokuchi (E-mail: shigeru@nagasaki-u.ac.jp)

(C)2016 The Society of Physical Therapy Science. Published by IPEC Inc.

This is an open-access article distributed under the terms of the Creative Commons Attribution Non-Commercial No Derivatives (by-nc-nd) License $<$ http://creativecommons.org/licenses/by-nc-nd/4.0/>.
} 
The maintenance of teeth and oral health plays an important role in the maintenance of the overall health of the elderly ${ }^{6,7)}$. Most individuals lose their teeth as they age, and occlusal imbalance due to tooth loss in older adults is reportedly associated with deterioration in physical function, and influences both disabilities in activities of daily living and the occurrence of falls ${ }^{8,9)}$. These findings suggest that reduction of occlusal imbalance may be effective for the improvement of the physical function of the elderly.

Sport medicine research has shown that fitting an interocclusal splint over individuals' teeth can improve motor performance $^{10,11)}$. Interocclusal splints lead to stable occlusal contact and reduce occlusal imbalance ${ }^{11,12)}$, and several studies have investigated the effects of an interocclusal splint on physical function ${ }^{13-15)}$. Researchers have reported that individuals with an interocclusal splint show greater lower extremity muscle strength and balance ability than those without an interocclusal splint $\left.^{13}, 14\right)$. These positive effects of an interocclusal splint on physical function may be related to an increase in the afferent impulses from periodontal mechanoreceptors and muscle spindles, facilitated by teeth clenching with stable occlusal contact. Previous studies have reported that the increase in these afferent inputs due to teeth clenching influences whole body muscles, and head and neck muscles, via the central nervous system, and results in improvement of physical function, because of more effective regulation of motor outputs ${ }^{9,15)}$.

The findings of these previous studies suggest that resistance training performed with an interocclusal splint may effectively improve physical function. However, the effectiveness of resistance training for the elderly, performed with an interocclusal splint compared with training without one, has not been fully investigated and remains unclear. Thus, we hypothesized that resistance training for elderly community-dwellers performed with an interocclusal splint would result in greater lower extremity muscle strength and better balance than resistance training performed without an interocclusal splint. The aim of this study was to test this hypothesis.

\section{SUBJECTS AND METHODS}

Elderly persons using community day centers twice per week in the Japanese city of Nagasaki were enrolled in this study. Nine day centers where physical therapists worked together with community care staff were selected. The physical therapists were asked to choose potential participants over the age of 65 years who were living at home, able to walk with or without a cane, and had at least four risk factors, as identified using the fall assessment questionnaire designed by Suzuki ${ }^{16)}$. This questionnaire has 15 items, and predicted falls with a sensitivity and specificity of $59.4 \%$ and $83.1 \%$, respectively, when the cutoff points of the four risk factors were used ${ }^{17}$. Therefore, this questionnaire has been widely adopted by community care staff for the assessment of the fall risk of elderly Japanese ${ }^{18)}$.

Participants who had participated in exercise at least four times a month prior to the intervention, and who had musculoskeletal, neurological or cardiovascular disorders that might have been aggravated by exercise, were excluded. Participants who were unable to respond to interview questions because of cognitive impairment were also excluded.

Written informed consent was obtained from each participant in accordance with the guidelines approved by the Nagasaki University Graduate School of Medicine and the Declaration of Human Rights, Helsinki, 2008.

This study had a randomized controlled trial design and was performed between April 2010 and September 2014. Participants who met the inclusion and exclusion criteria were randomly divided into two groups using the sealed envelope method $^{19)}$. The two groups were an intervention group, which performed resistance training with an interocclusal splint (27HA5900, Mizuno Corporation, Osaka, Japan), and a control group, which performed resistance training without an interocclusal splint. The division into groups was done after the baseline assessment. Physical therapists working in the day centers assessed the participants and implemented the intervention program.

The resistance training program comprised a 40-min session performed twice a week for 12 weeks using machines intended to increase lower extremity muscle strength. Three types of machines were used: a leg press machine, a hip abduction/ adduction machine, and a leg extension machine.

The exercise program comprised $10 \mathrm{~min}$ of warm-up, $20 \mathrm{~min}$ of resistance training, and $10 \mathrm{~min}$ of cool-down. The intensity of the resistance training was subjectively evaluated using the Borg Scale and was gradually increased ${ }^{20}$. The intensity in the period from 0 to 2 weeks after the start of the intervention was "fairly light", based on a score of 11 points on the Borg Scale; and in the period from 2 to 12 weeks after the start of the intervention was "somewhat difficult", based on a score of 13 points on the Borg Scale. Resistance training comprised four sets of 10 repetitions and was conducted using a training manual. The above training protocol was described in our previous study which measured its effects on physical function ${ }^{21)}$.

The interocclusal splint used in the intervention group becomes soft when it is soaked in hot water. The participants in the intervention group fitted these splints over their teeth and performed the above resistance training program while voluntarily clenching their teeth. The participants in the control group did not use these splints and performed the above resistance training program while voluntarily clenching their teeth.

Outcome measures were assessed using the following physical function performance tests: the chair stand test (CST) ${ }^{22)}$, the timed up and go test (TUG) ${ }^{23)}$, and the one-leg standing test (OLST) ${ }^{24)}$. Before commencing the study, the physical therapists received training from one of the authors $(\mathrm{TH})$ on the assessment protocols. These tests were conducted twice, and the best score was recorded. Physical function performance tests were conducted before the intervention and every 2 weeks after the start of the intervention. 
Psychological status was evaluated before the intervention using the 15 -item version of the Geriatric Depression Scale $\left(\right.$ GDS-15) ${ }^{25}$ and the modified Falls Efficacy Scale (FES) ${ }^{18)}$, translated into Japanese, to identify whether psychological status was associated with physical function performance. These assessments were self-administered, with guidance from the care staff at the day centers when needed.

Statistical analyses were performed using SPSS 22.0 for Windows (SPSS Inc., Armonk, NY, USA). The effect of the intervention over time on outcome measures was investigated using an intention-to-treat analysis. The unpaired t-test was used to evaluate significant differences in age, height, body weight, and physical function performance tests between the two groups prior to the intervention. The $\chi^{2}$ test was used to compare the gender distributions and the proportion of participants who dropped out between the two groups. The Mann-Whitney U test was used to assess differences between the two groups in terms of the GDS-15 and FES scores prior to the intervention.

The effect of exercise on each physical function performance test was analyzed using a 2 (group: intervention group and control group) $\times 7$ (time: baseline, and 2, 4, 6, 8, 10, and 12 weeks after the start of the intervention) analysis of variance. Post hoc, the Bonferroni test was used to assess which group or time periods showed significant differences. A two-sided $p$ value of $<0.05$ was considered significant.

\section{RESULTS}

A flowchart outlining study participation is shown in Fig. 1. In total, 178 individuals were screened as potential participants. Ninety of these 178 potential participants were excluded because they refused to participate in the study $(n=24)$ or failed to meet the inclusion criteria $(\mathrm{n}=66)$. The remaining individuals $(\mathrm{n}=88)$ were enrolled in the study and were randomly allocated to either the intervention group $(n=45)$ or the control group $(n=43)$. Seven participants $(8.0 \%)$ withdrew from the trial. One participant in the intervention group was admitted to hospital because of a serious illness (pneumonia), and another three participants withdrew because of social problems. One participant in the control group was admitted to hospital because of a serious illness (pneumonia), and another two participants withdrew because of social problems. There were no significant differences between the two groups in terms of withdrawal from the study $(\mathrm{p}=0.636)$. No participants dropped out as a result of the resistance training program itself. In short, 81 of 88 participants completed the 12 -week intervention: 41 in the intervention group and 40 in the control group.

During the intervention, participants in the intervention and control groups who completed the study attended $91.3 \%$ and $90.8 \%$ of the training sessions, respectively. There was no significant difference between the two groups in terms of program attendance $(\mathrm{p}=0.901)$.

The baseline characteristics of the participants are summarized in Table 1. There were no significant differences between the two groups in terms of age, gender, physical function performance, or psychological status ( $>0.333$ ).

Table 2 shows the changes in physical function performance of the two groups over the 12 weeks. There was a significant group $\times$ time interaction for the OLST $(\mathrm{p}=0.045)$, but, there were no significant group $\times$ time interactions for the CST or TUG $(\mathrm{p}=0.217$ and $\mathrm{p}=0.342$, respectively).

The mean values of the OLST from 8 to 12 weeks in the intervention group were significantly better than those in the control group $(\mathrm{p}<0.05)$. Within the intervention group, the mean values from 8 to 12 weeks showed significant improvement over those before the intervention $(\mathrm{p}<0.002)$. Within the control group, there was no significant difference in the mean values between before and at any time during the intervention.

There were no significant differences in the CST or TUG during the 12 weeks between the two groups. Within both groups, the mean values at 6 to 12 weeks showed significant improvement compared with before the intervention $(p<0.002)$.

\section{DISCUSSION}

The main finding of this randomized controlled trial is that resistance training effectively improved the physical function of elderly persons using community day centers. Specifically, the OLST, which is considered a marker of balance ability ${ }^{24)}$, exhibited a significant group $\times$ time interaction, whereas, the CST and TUG, markers of lower extremity muscle strength and walking ability ${ }^{22,23)}$, exhibited no significant group $\times$ time interactions.

The mean values of the OLST from 8 to 12 weeks after the start of the intervention were significantly better in the intervention group than in the control group. Within the intervention group, the mean values from 8 to 12 weeks after the start of the intervention were significantly better than those before the intervention. However, within the control group, there was no significant difference in the mean values between before and at any time during the intervention. Similarly, there were no significant differences in the CST or TUG during the 12 weeks between the two groups. Within both groups, however, the mean values from 6 to 12 weeks after the start of the intervention were significantly better than those before the start of the intervention. These results suggest that resistance training is effective at enhancing lower extremity muscle strength and walking ability, and that resistance training with an interocclusal splint is more effective at improving balance ability than resistance training without an interocclusal splint.

Interocclusal splints improve occlusal imbalance and facilitate teeth clenching because of stable occlusal contact ${ }^{11,12)}$. Regarding the mechanism behind the improvement in balance ability in the intervention group, several studies have reported 


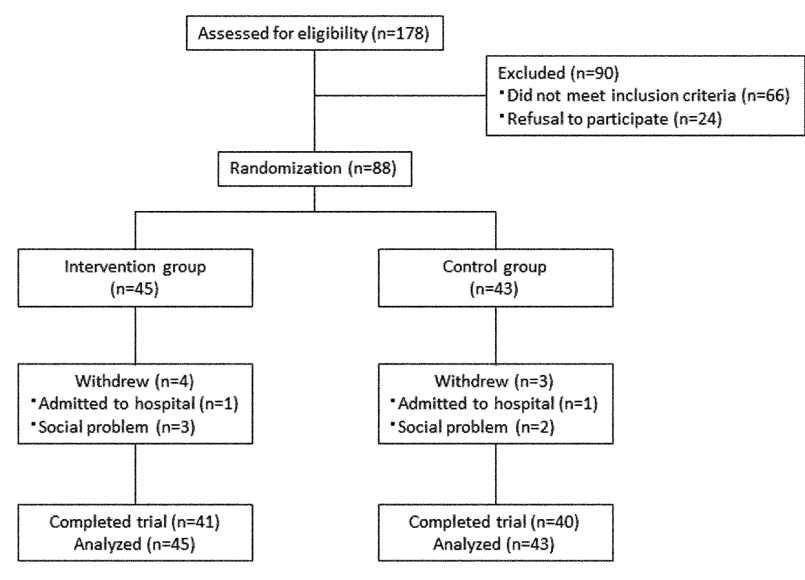

Fig. 1. Flowchart outlining the number of participants in each phase of the study
Table 1. Baseline characteristics of the study participants

\begin{tabular}{lcc}
\hline Characteristics & $\begin{array}{c}\text { Intervention } \\
\text { group }(\mathrm{n}=45)\end{array}$ & $\begin{array}{c}\text { Control group } \\
(\mathrm{n}=43)\end{array}$ \\
\hline Age (years) & $79.9 \pm 6.9$ & $78.4 \pm 7.0$ \\
Female, $\mathrm{n}(\%)$ & $24(53.3)$ & $26(60.0)$ \\
Height $(\mathrm{cm})$ & $153.9 \pm 10.4$ & $153.2 \pm 10.3$ \\
Weight $(\mathrm{kg})$ & $56.5 \pm 12.4$ & $53.8 \pm 8.6$ \\
GDS-15 score (points) & $3.5 \pm 3.1$ & $2.8 \pm 2.9$ \\
FES score (points) & $31.8 \pm 5.4$ & $33.3 \pm 6.2$ \\
CST (sec) & $13.4 \pm 6.3$ & $12.9 \pm 4.7$ \\
TUG (sec) & $11.2 \pm 5.0$ & $11.6 \pm 4.5$ \\
OLST (sec) & $5.9 \pm 3.4$ & $5.8 \pm 5.7$ \\
\hline
\end{tabular}

Values are expressed as mean \pm standard deviation (SD).

GDS-15: 15-item version of Geriatric Depression Scale; FES: Falls Efficacy Scale; CST: Chair Stand Test; TUG: Timed Up and Go test; OLST: One-Leg Standing Test

Table 2. Comparison of physical function performances of the two groups during the intervention period

\begin{tabular}{lccccccc}
\hline Item & Baseline & $\begin{array}{c}\text { After } \\
2 \text { weeks }\end{array}$ & $\begin{array}{c}\text { After } \\
\text { 4 weeks }\end{array}$ & $\begin{array}{c}\text { After } \\
6 \text { weeks }\end{array}$ & $\begin{array}{c}\text { After } \\
8 \text { weeks }\end{array}$ & $\begin{array}{c}\text { After } \\
10 \text { weeks }\end{array}$ & $\begin{array}{c}\text { After } \\
12 \text { weeks }\end{array}$ \\
\hline CST (sec) & & & & & & & \\
$\quad$ Intervention group & $13.4 \pm 6.3$ & $12.0 \pm 5.6$ & $10.8 \pm 3.9$ & $11.0 \pm 4.3^{\mathrm{b}}$ & $11.4 \pm 5.4^{\mathrm{b}}$ & $10.4 \pm 4.5^{\mathrm{b}}$ & $10.1 \pm 4.4^{\mathrm{b}}$ \\
$\quad$ Control group & $12.9 \pm 4.7$ & $12.1 \pm 4.8$ & $11.6 \pm 4.2$ & $11.7 \pm 4.5^{\mathrm{b}}$ & $11.2 \pm 4.2^{\mathrm{b}}$ & $10.9 \pm 4.2^{\mathrm{b}}$ & $10.7 \pm 4.8^{\mathrm{b}}$ \\
TUG (sec) & & & & & & \\
$\quad$ Intervention group & $11.2 \pm 5.0$ & $10.9 \pm 5.1$ & $10.5 \pm 5.1$ & $10.4 \pm 4.8^{\mathrm{b}}$ & $10.2 \pm 4.7^{\mathrm{b}}$ & $9.8 \pm 4.1^{\mathrm{b}}$ & $9.9 \pm 4.2^{\mathrm{b}}$ \\
$\quad$ Control group & $11.6 \pm 5.8$ & $10.7 \pm 5.0$ & $10.6 \pm 4.8$ & $10.4 \pm 4.4^{\mathrm{b}}$ & $10.5 \pm 4.8^{\mathrm{b}}$ & $10.5 \pm 5.7^{\mathrm{b}}$ & $9.9 \pm 4.8^{\mathrm{b}}$ \\
OLST (sec)* & & & & & & & \\
$\quad$ Intervention group & $5.9 \pm 3.4$ & $7.2 \pm 5.4$ & $9.0 \pm 8.9$ & $9.6 \pm 10.1$ & $9.8 \pm 6.5^{\mathrm{ab}}$ & $10.7 \pm 10.7^{\mathrm{ab}}$ & $12.0 \pm 10.5^{\mathrm{ab}}$ \\
$\quad$ Control group & $5.8 \pm 4.4$ & $5.7 \pm 3.8$ & $5.8 \pm 4.2$ & $6.6 \pm 4.2$ & $7.1 \pm 5.0$ & $7.0 \pm 6.9$ & $7.5 \pm 8.9$ \\
\hline
\end{tabular}

Values are expressed as mean \pm standard deviation (SD).

CST: Chair Stand Test; TUG: Timed Up and Go test; OLST: One-Leg Standing Test

* Significant group $\times$ time interaction $(\mathrm{p}<0.05)$.

a Significant differences between the two groups, ${ }^{\mathrm{b}}$ Significant differences from baseline

that teeth clenching influences contracture of the neck and trunk muscles, and that these muscles co-contracted with the masseter muscle during teeth clenching ${ }^{26-28)}$. Miyahara et al. ${ }^{29)}$ investigated the effect of teeth clenching on lower extremity muscle activity by measuring the modulation of the Hoffmann reflex (H-reflex) amplitude. They reported that the soleus H-reflex was facilitated by voluntary teeth clenching, and suggested that peripheral factors, including afferent sensory inputs from periodontal mechanoreceptors and central commands for teeth clenching, play an important role in the facilitation of the soleus H-reflex. Kawakubo et al. ${ }^{30}$ investigated the cortical activations of the enhancement of handgrip force during teeth clenching using functional magnetic resonance imaging (fMRI). They reported that activation in the supraspinal motor cortices, including the hand region in the primary motor cortex, anterior cerebellum and cingulate motor area/supplementary motor area, was enhanced by teeth clenching. Thus, previous research suggests that both central motor commands and afferent impulses from periodontal mechanoreceptors and muscle spindles are facilitated by teeth clenching ${ }^{29,}{ }^{30)}$. This suggests that these mechanisms influence contracture of the neck and trunk muscles in a way that increases neck and trunk muscle strength and improves neck and trunk stability, and that balance ability in the intervention group improved because of the above-described mechanisms. However, investigating the possible underlying mechanisms is beyond the scope of this paper.

Previous studies have reported that resistance training effectively improves the muscle strength and walking ability of the elderly $^{3-5)}$. However, whether resistance training effectively improves balance ability remains unclear ${ }^{31,32)}$. This change in physical function among the participants in the control group is similar to these previous studies.

Four (8.8\%) participants withdrew from the intervention group, and three (7.0\%) participants withdrew from the control group for the previously noted reasons. Of the participants who did not withdraw from the study, $91.3 \%$ and $90.8 \%$ of the intervention and control group subjects, respectively, completed all the study exercises. There were no significant differences between the two groups in terms of study withdrawal or program attendance. Based on these results, it appears that the 
resistance training was widely accepted by the participants and is safe and feasible as a service provided at day centers.

This study had some limitations. First, the same physical therapists assessed the participants and also conducted the intervention programs. Therefore, there is a possibility that our results were influenced by the physical therapists' expertise and/ or reporting bias at each day center. However, the physical therapists who participated in the study received the same level of training from a senior physical therapist before initiating the trial, and the exercise program was conducted using a training manual. Therefore, we propose that the physical therapists' expertise had a minimal effect on the study results. A second limitation is that the number of falls during the intervention period was not recorded. Thus, the effect of the resistance training program with an interocclusal splint on fall occurrence could not be determined. Nevertheless, improved physical function is associated with fewer falls in older adults ${ }^{33}$. A third limitation is that the intensity of the resistance training was determined using the Borg Scale. Therefore, the differences in outcome measures in both groups may have been caused by the resistance intensity of the machines. A fourth limitation is that neither the neck and trunk muscle strength nor body sway was assessed. Additionally, occlusal conditions, such as tooth loss and the patterns of occlusal contact of the participants, were not assessed in the present study. Therefore, as mentioned above, the mechanisms behind the improvement in balance ability could not be investigated in the intervention group. Further studies are needed to assess neck, trunk, masseter muscle strength, and body sway using appropriate equipment, such as a hand-held dynamometer, phagodynamometer, and a stabilograph, in addition to evaluating the occlusal conditions in detail.

In conclusion, resistance training for elderly persons attending community day centers is effective at enhancing the lower extremity muscle strength and walking ability, and resistance training with an interocclusal splint is more effective at improving balance ability than resistance training without an interocclusal splint. Moreover, resistance training was widely accepted by the day-center clients, suggesting that resistance training performed with an interocclusal splint is effective and feasible as a service provided at day centers.

\section{ACKNOWLEDGEMENTS}

The authors are grateful for the cooperation of all the participants in this study. The authors express their gratitude to Shingo Ishitobi, PhD, for guidance in this research. This study was supported by a Grant-in-Aid for Scientific Research (No. 23500585) from the Ministry of Education, Culture, Sports, Science and Technology of Japan.

\section{REFERENCES}

1) Wada Y, Sakuraba K, Kubota A: Effect of the long-term care prevention project on the motor functions and daily life activities of the elderly. J Phys Ther Sci, 2015, 27: 199-203. [Medline] [CrossRef]

2) Morala D, Shiomi T: Assessing reliability and validity of physical performance test for the Japanese elderly. J Phys Ther Sci, 2004, 16: 15-20. [CrossRef]

3) Latham NK, Bennett DA, Stretton CM, et al.: Systematic review of progressive resistance strength training in older adults. J Gerontol A Biol Sci Med Sci, 2004, 59: 48-61. [Medline] [CrossRef]

4) Liu CJ, Latham NK: Progressive resistance strength training for improving physical function in older adults. Cochrane Database Syst Rev, 2009 , 8: CD002759. [Medline]

5) Valenzuela T: Efficacy of progressive resistance training interventions in older adults in nursing homes: a systematic review. J Am Med Dir Assoc, 2012, 13: 418-428. [Medline] [CrossRef]

6) Morozumi K, Nishiya T, Yasuda A, et al.: Effects of bite with and without dentures on soleus H-reflex in the elderly. J Phys Ther Sci, 2002, 14: 51-55. [CrossRef]

7) Hirao A, Murata S, Murata J, et al.: Relationships between the occlusal force and physical/cognitive functions of elderly females living in the community. $\mathrm{J}$ Phys Ther Sci, 2014, 26: 1279-1282. [Medline] [CrossRef]

8) Okuyama N, Yamaga T, Yoshihara A, et al.: Influence of dental occlusion on physical fitness decline in a healthy Japanese elderly population. Arch Gerontol Geriatr, 2011, 52: 172-176. [Medline] [CrossRef]

9) Moriya S, Muramatsu T, Tei K, et al.: Relationships between oral conditions and physical performance in a rural elderly population in Japan. Int Dent J, 2009, 59: 369-375. [Medline]

10) Moriya S, Notani K, Murata A, et al.: Analysis of moment structures for assessing relationships among perceived chewing ability, dentition status, muscle strength, and balance in community-dwelling older adults. Gerodontology, 2014, 31: 281-287. [Medline] [CrossRef]

11) Pae A, Yoo RK, Noh K, et al.: The effects of mouthguards on the athletic ability of professional golfers. Dent Traumatol, 2013, 29: 47-51. [Medline] [CrossRef]

12) Grosdent S, O'Thanh R, Domken O, et al.: Dental occlusion influences knee muscular performances in asymptomatic females. J Strength Cond Res, 2014, 28: 492-498. [Medline] [CrossRef]

13) Yamaga T, Yoshihara A, Ando Y, et al.: Relationship between dental occlusion and physical fitness in an elderly population. J Gerontol A Biol Sci Med Sci, 2002, 57: M616-M620. [Medline] [CrossRef]

14) Bracco P, Deregibus A, Piscetta R: Effects of different jaw relations on postural stability in human subjects. Neurosci Lett, 2004, 356: 228-230. [Medline] [CrossRef]

15) Hellmann D, Giannakopoulos NN, Blaser R, et al.: The effect of various jaw motor tasks on body sway. J Oral Rehabil, 2011, 38: 729-736. [Medline] [CrossRef] 
16) Suzuki T: Questionnaire for falls assessment of elderly people and its application. Health assessment manual. Tokyo: Kosei Kagaku Kenkyusho, 2000, pp 142-163 (in Japanese).

17) Demura S, Sato S, Shin S, et al.: Setting the criterion for fall risk screening for healthy community-dwelling elderly. Arch Gerontol Geriatr, 2012 , 54: $370-373$. [Medline] [CrossRef]

18) Hirase T, Inokuchi S, Matsusaka N, et al.: Effects of a balance training program using a foam rubber pad in community-based older adults: a randomized controlled trial. J Geriatr Phys Ther, 2015, 38: 62-70. [Medline] [CrossRef]

19) Doig GS, Simpson F: Randomization and allocation concealment: a practical guide for researchers. J Crit Care, 2005, 20: 187-191, discussion 191-193. [Medline] [CrossRef]

20) Ikezoe T, Tsutou A, Asakawa Y, et al.: Low intensity training for frail elderly women: long-term effects on motor function and mobility. J Phys Ther Sci, 2005, 17: 43-49. [CrossRef]

21) Inokuchi S, Matsusaka N: Feasibility and effectiveness of a low intensity machine-based exercise program within the community for prevention of falls to the frail older people: a multi-center controlled trial. Age Ageing, 2008, 37: ii36-ii38.

22) Gardner MM, Buchner DM, Robertson MC, et al.: Practical implementation of an exercise-based falls prevention programme. Age Ageing, 2001, 30: 77-83. [Medline] [CrossRef]

23) Podsiadlo D, Richardson S: The timed "Up \& Go": a test of basic functional mobility for frail elderly persons. J Am Geriatr Soc, 1991, 39: 142-148. [Medline] [CrossRef]

24) Vellas BJ, Wayne SJ, Romero L, et al.: One-leg balance is an important predictor of injurious falls in older persons. J Am Geriatr Soc, 1997, 45: 735-738. [Medline] [CrossRef]

25) Sheikh JI, Yesavage JA: Geriatric Depression Scale (GDS): recent findings and development of a shorter version. In: Brink TL (ed.), Clinical gerontology: a guide to assessment and intervention. New York: Haworth Press, 1986, pp 165-173.

26) Ehrlich R, Garlick D, Ninio M: The effect of jaw clenching on the electromyographic activities of 2 neck and 2 trunk muscles. J Orofac Pain, 1999 , 13 : 115-120. [Medline]

27) Moon HJ, Goo BO, Cho SH: The effect of cocontraction of the masticatory muscles during neck stabilization exercises on thickness of the neck flexors. J Phys Ther Sci, 2015, 27: 659-661. [Medline] [CrossRef]

28) Shimazaki K, Matsubara N, Hisano M, et al.: Functional relationships between the masseter and sternocleidomastoid muscle activities during gum chewing. Angle Orthod, 2006, 76: 452-458. [Medline]

29) Miyahara T, Hagiya N, Ohyama T, et al.: Modulation of human soleus H reflex in association with voluntary clenching of the teeth. J Neurophysiol, 1996, 76: 2033-2041. [Medline]

30) Kawakubo N, Miyamoto JJ, Katsuyama N, et al.: Effects of cortical activations on enhancement of handgrip force during teeth clenching: an fMRI study. Neurosci Res, 2014, 79: 67-75. [Medline] [CrossRef]

31) Orr R, Raymond J, Fiatarone Singh M: Efficacy of progressive resistance training on balance performance in older adults : a systematic review of randomized controlled trials. Sports Med, 2008, 38: 317-343. [Medline] [CrossRef]

32) Yu W, An C, Kang H: Effects of resistance exercise using theta-band on balance of elderly adults: a randomized controlled trial. J Phys Ther Sci, 2013, 25: 1471-1473. [Medline] [CrossRef]

33) Guideline for the prevention of falls in older persons. American Geriatrics Society, British Geriatrics Society, and American Academy of Orthopaedic Surgeons Panel on Falls Prevention. J Am Geriatr Soc, 2001, 49: 664-672. [Medline] [CrossRef] 